\title{
Predicting Post mortem Interval using Discriminant Function Analysis of the Succession Pattern of Necrophagous Insects
}

\author{
*ALAFIA, A.O., ANIKWE', J.C., DENLOYE², A.A., AJELARA², K.O., \\ MAKANJUOLA', W.A. AND AWOSANYA', T. \\ 'Department of Zoology, Faculty of Science, University of Lagos, Akoka, Yaba. \\ ${ }^{2}$ Department of Zoology and Environmental Biology, Faculty of Science, \\ Lagos State University, Ojo, Lagos. \\ ${ }^{3}$ Department of Biostatistics, Faculty of Science, Obafemi Awolowo University, Ile-Ife.
}

Nig. J. Entomol. 33: 57-65(2017)

\begin{abstract}
Estimation of postmortem interval (PMI) is an integral part of most death investigations. Succession pattern of insects associated with decomposing animals is one of the methods used for PMI prediction. This study aims to design a model with which PMI may be predicted in Lagos and Kaduna States using the successional pattern of insects on decomposing carrions in the two regions. Seventy percent of the data on the succession pattern of insects collected from decomposing pigs were fed into discriminant analysis to generate a classification model while the remaining $30 \%$ of the data was used to test the model. Twenty six variables were used to classify time of death into nine groups (0-1,1-2,2-3,3-4,4-5,5-6,6-7, 7-8 and over 8 weeks). Discriminant function analysis revealed that empty calliphorid puparium around carrion (0.675), Tenebrionidae (0.598), Histeridae (0.582), adult Calliphoridae (-0.509) and Scarabidae (0.50) were the five most discriminating variables for predicting postmortem interval. The model $\left(\mathrm{LD}_{1}\right)$ generated was tested with blind data to time of death with an upper accuracy limit of $79.7 \%$.
\end{abstract}

Keywords: Postmortem interval, Succession, Discriminant analysis.

\section{INTRODUCTION}

The most commonly used and required information that can be provided by forensic entomological work is the estimated minimum time of death also known as the Postmortem Interval (PMI). In forensic entomology, it is generally accepted that there is actually no scientific way to precisely determine the exact period of time since death, hence, an estimation of the Period of Insect Activity (PIA) on the body is determined. Period of Insect Activity reflects the minimum period of time since death or Postmortem Interval (PMI) but does not precisely determine the time of death. In most cases, arthropods are used as biological

*Corresponding author:

Email: honcylafiak yahoo.com indicators of PMI and have been shown to offer more reliable estimations for longer PMI intervals. From 72 hours after death, forensic entomology is usually the most accurate and in some cases the only method that can be used for estimation of PMI (Kashyap and Pillai, 1989; Tempelman-Kluit, 1993).

In recent years, entomological techniques used in postmortem interval estimation have developed and become increasingly important thereby resulting in their successful application. The calculations of PMI by entomological techniques fit well with the time intervals established by other methods (Smith, 1986: Goff et al., 1988: (atts and Haskell, 1990). Kashyap and Pillai (1989) examined and analysed 16 insect-infested cadavers to evaluate the 
reliability of the entomological method in estimation of time elapsed since death in relation to other medico-legal approaches. Their results revealed that the entomological method was statistically more reliable and superior when compared to other prevalent methods.

Insect scientists are increasingly being called upon to apply their expertise in criminal and civil proceedings and even constitute part of forensic laboratories and medicolegal investigation teams (Lord and Rodriquez, 1989).

An entomologically derived PMI is based on two general principles which may be complementary, although each may be better suited for use during different stages of carrion decomposition. The first method involves using developmental data of certain species commonly found on decomposing carrion in a region to estimate the age of a carrion, or the postoviposition interval (Wells and LaMotte, 2010). This method is used in initial decomposition stages, with Diptera species from Calliphoridae family as the main indicators. The ages of insect immature stages found on a dead body can provide evidence for the estimation of a minimum PMI ranging from day one up to more than one month, depending on the insect species involved and the climatic conditions at the death scene.

The second method is to predict PMI based on the succession of arthropods present on a carrion (Anderson, 2001; Wells and LaMotte, 2010). This method can be used in long postmortem intervals (Catts and Goff, 1992) weeks, months or even years after death (Anderson, 1995). It is based on the premise that insects found on decomposing animal remains so in a predictable manner as decomposition progresses. Hence, it requires detailed records of the time at which each species arrives on carrions as they decay and not the development records.

Succession studies, usually made with animal models such as pigs provide the reference data used to compare with the taxal collected on human remains (Wells and LaMotte, 2010). Ecological suceessions are however dynamic and less predictable than insect derelopment (Braack, 1981; Wells and LaMotte, 2010). There are many parameters that can affect the timing and species composition of the carrion fauna, therefore research is highly required to develop a geographical database of insect succession on carrion in a variety of habitats and scenarios for forensic investigation.

The proper identification of the insects and arthropod species of forensic importance is the most crucial element in the field of forensic entomology. In order to apply entomological evidence to the estimation of the postmortem interval based on the stages of succession, it is essential to precisely identify the species of insects attracted to the remains and also note the succession patterns typical of seasonal periods (Goff, 2010: Sharmaet al., 2015). It is the species identification that allows for proper developmental data and distribution ranges which is to be applied to proper investigation procedures. If the species determination is incorrect then the estimated postmortem interval will be invalid (Byrd and Castner, 2010).

Watson (2004) established a statistical technique for distinguishing between deer, bear, swine and alligator carrions using the insect taxa collected during their scomposition. The study identified the insect axa having the highest discriminating powers toreach animal type using discriminant analysis which showed that bear, deer and swine werwicurately classified $66.67 \%$, $69.29 \%$ and $74.71 \%$ of the time respectively while alligatorcartion was inaceurately classified.

Using generalized additive model of gene expression, Foran (2007) precisely determined the age of Lucilica sericata as a method of PMI estimation. Nine genes were assessed for their informative kerel using quantitative Polymerase chain reaction ( $P(R)$. The model was tested in a blind study to predict the age of 90 flies in which results revealed rarying level of accuracy with more gene expression information provided.

The aim of the present work is to establish a statistical model with which PMII would be predicted using the succession pattern of insects. 


\section{MATERIALSAND METHODS}

\section{Study Sites}

The study was conducted during the wet and dry seasons in Lagos and Kaduna States, representing two different biogeoclimatic zones of Nigeria using 24 pig carrions. of known PMI.

\section{Data Collection Procedure}

All carrions were monitored immediately after death occurred, for insect activities and arrival pattern. Insects were collected using three sampling methods: Aerial sweep net, handpicking off carrions and surrounding soil and pitfall traps. Twenty insect larvae were collected from each pig carrion into pots containing hot water and thereafter transferred into vials containing 70\% ethanol to prevent the larvae from shrinking.

Average weight of dipteran larvae found on decomposing pig carrions were determined by collecting 30 larvae randomly from each pig carrions daily which were killed by immersion into hot boiling water for $30 \mathrm{~s}$ and thereafter removed into $70 \%$ ethanol. Ten representative larvae per pig carrion per location were placed on filter paper, air dried, and they were thereafter weighed using a Mettler( $\overline{\mathbb{B}}$ PM 400 (g) digital weighing balance with 0.01 gaccuracy.

Larval lengths were measured in pixel and with the aid of a calibrated hand held digitized microscope Zarbeco $(\hat{\mathbb{R}})$ with magnification of $\mathrm{x} 40$ and $\mathrm{x} 140$ and then converted into $\mathrm{mm}$.

Larval length in $\mathrm{mm}=$

$$
M P I * 2.54) \div D P I
$$

Where

DPI $($ Dots perinch $)=300$

MPV (Measured Pixel Value)

(www:dallinjones.com)

Insects were identilied by comparing them with type specimens at the insectary of the
Department of Crop Protection, Faculty of Agriculture. Ahmadu Bello University, Zaria and using keys from previous studies. Contirmation of the identified insects was carried out at the museum of the Department of Crop Protection, Faculty of Agriculture, Ahmadu Bello University, Zaria.

\section{Statistical Analysis}

All Postmortem interval was predicted using Discriminant Function Analysis (DA). A classification model used to predict group membership based on a linear combination of the interval variables was established for PMI prediction using the succession pattern of insects collected in the study.

The hypothesis tested was that there is a linear combination of variables which when appropriately weighted will maximally discriminate between members of nine groups and permit new cases to be classified into the groups. The variables used in the prediction were based on the occurrence pattern of selected insect families on pig carrions at different stages of decomposition. The independent variables are the predictors ( 26 different variables based on the occurrence pattern of insect families on the carrion) (Table 1) and the dependent variables are the groups (weeks of decomposition) which are categorized into nine classes: Weeks: 1, 2, 3, 4, 5, $6,7,8$, and over 8 Weeks.

The data used in the analyses contained the following information for each sampling event: season, location, stage of decomposition, day (i.e., day of decomposition), week of decomposition and number of specimens collected. The variables $X_{1}-X_{1}$ as well as variables $X_{210}-X_{20}$ are a function of numbers or quantity observed (equation 1), while variables $X_{L}$ is a function of size (length) (equation 2) and variable $X_{1}$ is a function of weight (equation 2). The variables were assigned with classification score $C_{5}$ ranging from $0-5$, depending on the number. length and weight of insect life stages observed on the carrions. 
Table 1: Predictor Variables

\begin{tabular}{|c|c|c|}
\hline No & Variables & Fxperimental Premise \\
\hline$x_{1}$ & Presence of dipteran larvae & $!(n)$ \\
\hline$x:$ & Presence of prepupa & $\int(n)$ \\
\hline$x_{;}$ & Presence of pupa & $!(n)$ \\
\hline$x_{4}$ & Larval aggregation on surface & ! (n) \\
\hline$x_{5}$ & Larval migration for pupation & ! (n) \\
\hline$x_{0}$ & Empty Calliphorid puparia & $\int(n)$ \\
\hline$x$ & Larvac buried under carrion & $!(n)$ \\
\hline$x_{s}$ & Presence of adult Musca domestica & ! (n) \\
\hline$x_{4}$ & Presence of adult Chrosomiasp. & $!(\mathrm{n})$ \\
\hline$x_{11}$ & Presence of adult Sarcophaga sp. & $!(n)$ \\
\hline$x_{11}$ & Presence of adultClerid, Necrobia sp. & $\lfloor(n)$ \\
\hline$x_{12}$ & Presence of adult Nicrophorus sp. & $\int(n)$ \\
\hline$x_{13}$ & Presence of adult Dermestes sp. & $\int(n)$ \\
\hline$x_{14}$ & Presence of Dermestes larrae & $\int(n)$ \\
\hline$x_{15}$ & Presence of Dermestes pupa & $\int(n)$ \\
\hline$x_{16}$ & Presence of adult Formicidae & $\int(n)$ \\
\hline$x_{17}$ & Empty Dermestes puparia & $!(n)$ \\
\hline$x_{18}$ & Average length of Dipteran larvae & $\int(1)$ \\
\hline$x_{19}$ & Average weight of Dipteran Larvae & $\int(w)$ \\
\hline$x_{20}$ & Presence of Carabidae & $\int(n)$ \\
\hline$x_{21}$ & Presence of Scarabidae & $\lceil(\mathrm{n})$ \\
\hline$x_{22}$ & Presence of Histeridae. & $\int(\mathrm{n})$ \\
\hline$x_{23}$ & Presence of Stapy hilinidae & $\int(n)$ \\
\hline$x_{24}$ & Presence of Melyris ahdominalis & $\int(n)$ \\
\hline$r_{25}$ & Presence of Coccinelidae & $\int(n)$ \\
\hline$x_{26}$ & Presence of Tenehrionidae & $\int(\mathrm{n})$ \\
\hline
\end{tabular}

Discriminant function analysis is a 2 -step process, which involves:

(1) Testing significance of a set of function and

(2) Classification.

Subsequently, the function with the highest proportion of trace was therefore used to predict membership in naturally oceurring groups using the formulae:

$$
\begin{aligned}
& n=0 \text { for } n i l, \\
& n=1 \text { for } \geq 3, \\
& n=2 \text { for } \leq 3 \leq 10, \\
& n=3 \text { for } \geq 10 \leq 20 \\
& n=4 \text { for } \geq 20 \leq 30 \\
& n=5 \text { for } \geq 30 .
\end{aligned}
$$

And

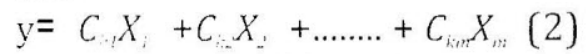

$$
\begin{aligned}
& y=P M I=f\left(x_{n}\right)---(1) \\
& \left.y=C_{n} X_{1}+C_{1} X_{-}+\ldots+C_{0, n} X_{n:--1}\right)
\end{aligned}
$$

Where $x_{1}=f(1)$ and measured in $\mathrm{mm}$ $\mathrm{I}=0$ when length of larvac is 0 $l=1$ when length of larvae is $\geq 0 \leq 5$ $1=2$ when length of larvace is $\geq 5 \leq 10$ $1=3$ when length of larvae is $\geq 10 \leq 15$

\section{Location $=\operatorname{Lagos}=1$ and Kaduna $=0$}

$1=4$ when length of larvac is $\geq 15 \leq 20$ $I=5$ when length of larvae is $\geq 20 \leq 25$

Where $x_{1}-x_{17}=f(n)$ and and 
Where: $x_{14}=f(w)$ in $\mu g$

$w=1$ when weight of larvae is $\geq 0.001 \leq 0.004$

$w=2$ when weight of larvae is $\geq 0.005 \leq 0.008$

$w=3$ when weight of larvae is $\geq 0.009 \leq 0.012$

$w=4$ when weight of larvae is $\geq 0.0013 \leq 0.018$

and

$x_{20}-x_{26}=1 n$

$\mathrm{n}=0$ for nil,

$\mathrm{n}=1$ for $\geq 3$,

$\mathrm{n}=2$ for $\leq 3 \leq 10$,

$\mathrm{n}=3$ for $\geq 10 \leq 20$

$\mathrm{n}=4$ for $\geq 20 \leq 30$

$\mathrm{n}=5$ for $\geq 30$,

* $\quad \mathrm{C}_{\mathrm{k}}$ is the classification score for group $\mathrm{k}$

* C's are the coefficients in table

Cross validation of the first discriminant function was carried out using $30 \%$ of the total succession observations (as blind samples), and accuracy of the result was tested using speciticity and sensitivity of classified data, where Specificity is the probability of true negatives and Sensitivity is the probability of true positives. Analysis and presentation of results was carried out using Microsoft excel, SPSS version 21 and 'R' rersion 3.0.2. Significant differences were established using ANOVA (a, $<<0.05$.

\section{RESULTS}

Fourty-two insect families were identified out of which 22 were of forensic importance and these insects belong to three insect orders; Diptera, Coleoptera and Hymenoptera. These insect families of forensic importance were collected from pig carrions as they decompose through five stages, namely; Fresh, Bloated, Active decay, Advanced decay and Skeletonized stages. Some of the insect families were common to the two study sites with certain insects found exclusively to either of the sites (Table 2). The

Table 2: Forensically important insect families collected from pig carrions in Ojo, Lagos and Samaru, Kaduna State

\begin{tabular}{|c|c|c|c|c|c|}
\hline Order & Family & Ojo & Samaru & Status & Stage of occurrence \\
\hline \multirow[t]{9}{*}{ Diptera } & Calliphoridae & $*$ & $*$ & $\mathrm{~N}$ & All stages \\
\hline & Drosophilidae & $*$ & - & $\mathrm{N}$ & Fresh \\
\hline & Fannidae & $*$ & - & $\mathrm{N}$ & Fresh \\
\hline & Muscidae & $*$ & $*$ & $\mathrm{~N}$ & All stages \\
\hline & Rhinnidae & $*$ & $*$ & $\mathrm{~N}$ & Fresh \\
\hline & Tachnidae & $*$ & $*$ & $\mathrm{~N}$ & Fresh \\
\hline & Tephritidae & $*$ & $*$ & $\mathrm{~N}$ & Fresh, Bloated \\
\hline & Sarcophagidae & $*$ & $*$ & $\mathrm{~N}$ & Fresh, Bloated. Active \\
\hline & Sphaeroceridae & $*$ & - & $\mathrm{N}$ & Fresh \\
\hline \multirow[t]{11}{*}{ Coleoptera } & Carabidac & $*$ & $*$ & $P$ & Adranced \\
\hline & Cleridae & $*$ & $*$ & $\mathrm{P}$ & Bloated, Active, Adranced \\
\hline & Coccinelidac & $*$ & $*$ & $\mathrm{P}$ & Active, Adranced \\
\hline & Dermestidae & $*$ & * & N.P & Bloated, Active, Adranced \\
\hline & Histeridae & $*$ & $*$ & N.P & Active, Advanced \\
\hline & Hydrophilidac & $*$ & $*$ & $P$ & Active, Adranced \\
\hline & Melyridae & - & $*$ & N.P & Active, Advanced \\
\hline & Tencbrionidae & $*$ & $*$ & N.P & Active, Adranced. Skeleton \\
\hline & Scarabidac & $*$ & - & N.P & Active, Adranced \\
\hline & Silphidae & $*$ & - & N.P & Active, Advanced \\
\hline & Staphylinidac & $*$ & $*$ & $\mathrm{P}$ & Active, Adranced \\
\hline Hymenoptera & Formicidae & $*$ & $*$ & N.P & All stages \\
\hline
\end{tabular}

$\mathrm{N}=$ Necrophatgous, $\mathrm{P}=$ Predators 
Table 3: Proportion of traced for discriminant functions

\begin{tabular}{llll}
\hline Function & Proportion of trace & $\%$ of trace & Singular valuc decomposition \\
\hline LD1 & 0.5648 & 56 & 11.176 \\
LD2 & 0.2379 & 24 & 7.102 \\
LD3 & 0.0895 & 8.95 & 4.51 \\
\hline
\end{tabular}

Table 4: Number of observations and pereent classified into weeks determined using first discriminant function

\begin{tabular}{lccll}
\hline WEEKS & Observation & \% Classified & Sensitivity \% & Specificity \% \\
\hline $\mathbf{1}$ & 16 & 93.75 & 93.9 & 97.2 \\
$\mathbf{2}$ & 6 & 66.67 & 66.67 & 95.65 \\
$\mathbf{3}$ & 8 & 42.85 & 37.50 & 100 \\
$\mathbf{4}$ & 7 & 85.71 & 85.7 & 95.6 \\
$\mathbf{5}$ & 4 & 66.67 & 25.00 & 97.92 \\
$\mathbf{6}$ & 2 & 100 & 100 & 94.00 \\
$\mathbf{7}$ & 2 & 0 & 0 & 98.00 \\
$\mathbf{8}$ & 4 & 75 & 33.33 & 93.88 \\
Over 8 & 3 & 66.67 & 33.33 & \\
Total & 56 & & & \\
Overall Accuracy & $\mathbf{5 2 . 6} \mathbf{\% - 7 9 . 7 \%}$ & & &
\end{tabular}

* Overall statistics: Accuracy $=0.673 ; \mathrm{P}$-value $6.46 \mathrm{c}-08 ; 95^{\circ} \% \mathrm{Cl}=(0.529,0.797)$. Specificity is probability of true negatives and sensitivity is the probability of true positives.

necrophagous insects which feed directly on the carrion and the predators that feed on the necrophagous insects and/or on the carrion itself were all included as predictor variables for PMI prediction (Table 3). The total number of observations recorded during the five stages of decomposition (i.e the total number of events captured throughout the studies which involves the predictor variables, $N=173$. More observations were recorded during active and adranced decay stages of decomposition which coincides with the $2^{\text {nd }}, 3^{\text {th }}, 4^{\text {th }}$ and $5^{\text {th }}$ weets of decomposition. During these stages the carrions attracted higher diversity of forensically important insects in greater abundance especially members of the order Coleoptera. The later stages of decomposition was characterized with less insect diversityhence fewer observations were recorded.

In the first step of the analysis. eight linear discriminant functions were generated from the nine groups to distinguish between the erents of each week. The first linear discriminant function (LD1) determined more than half $(56 \%)$ of the observation and hence has the highest proportion of trace and was therefore accepted as a suitable model for PMI prediction (Table 4).

The model identified tive observable variables having the highest predictive power for estimating PMI which were assigned with coefficient rating powers viz: presence of empty calliphorid puparia $(0.675)$. presence of Tenebrionidas $(0.598)$, presence of Histeridac (0.583), presence of adult Calliphoridae $(-0.509)$ and presence of Scarabidae $(0.50)$. The variables that had the lowest predictive powers were presence of adult clerid beetles ($0.01366)$ and presence of Dermestes sp. puparia (0.004.49). Location (0.484) also had higher predictive value than season (0.046).

The model (LDI) which specified that PMI was a linear combination of location. season. presence and/or absence of some insect species and their abundance level on pig carrions is shownas: 


$$
\begin{aligned}
& P H=L D 1=\text { locotion } \cdot 0.484-\operatorname{season} \cdot(0.046)-(0.042) \cdot x_{1}-(-0.085) \cdot x_{2} \\
& -0.037 \cdot x_{3}-0.047 \cdot x_{4}+(-0.031) \cdot x_{3}-0.675 \cdot x_{6}-0.142 \cdot x_{7} \\
& -(-0.465) \cdot x_{8}-(-0.51) \cdot x_{5}-0.336 \cdot x_{16}-(-0.014) \cdot x_{11} \\
& -(-0.22) \cdot x_{12}-0.195 \cdot x_{13}-0.296 \cdot x_{1 \div}-0.004 \cdot x_{1 \Sigma}-[-0.277] \\
& \cdot x_{1 E}-[-0.483] \cdot x_{15}-[-0.278] \cdot x_{1 E}-[-0.091] \cdot x_{15}-0.202 \cdot x_{20} \\
& -0.505 \cdot x_{21}-0.583 \cdot x_{22}-0.399 \cdot x_{23}-0.315 \cdot x_{24}-0.416 \cdot x_{23} \\
& -0.599 \cdot x_{2 \epsilon}
\end{aligned}
$$

\section{DISCUSSION}

The purpose of this study was to provide a statistical model for the prediction of PMI, using the succession pattern of insects on the carrions. The succession pattern of insects on the carrions followed the usual arrival pattern with the dipterans arriving earlier than the coleopterans and this was similar for both dry and wet seasons. The changes in carrion decomposition and succession trend of insect species is similar to observation of other works (Smith, 1986; Shi et al., 2009). The active decay stage of decomposition attracted more necrophagous species and hence predictions during this stages were more accurate as evident in the specificity and sensitivity levels of the predictions. Earlier studies have also shown that the active decay stage attracts higher diversity of insect species especially the Coleopterans (Smith, 1986; Anderson, 2001).

Although variations was observed in the species diversity between the two regions, this factor was considered in selecting the variables included in the model. Similar variations have been reported by previous researchers from studies conducted in different geographical regions. It is general knowledge that the geographical region determines the types of insect species that would be found in an area and their seasonal arailability.

All tested variables which included presence of calliphorid, puparia migration and average length of larvae were significant predictors of PMI in at least one model, though some exerted more influence on prediction than others. The inclusion of as much as 26 variables in the model helped to improve on the prediction performance. This finding is consistent with report of Wells and LaMotte (2017), who suggested that the importance of a covariate or the practical value of a response can be assessed based on predictive model performance.

The accuracy level of PMI predictions using training data was higher $(83.6 \%-94.9 \%)$, than the test data set $(52.9 \%-79.7 \%$.), these shows that the procedure adopted in the discriminant analysis which involves using part of the observation is also a means of improving the prediction performance and eliminating bias.This method has been reported as an appropriate unbiased means of statistical analyses (Wells et al. 2015).

Presence of empty Calliphorid puparium $\left(\mathrm{X}_{6}\right)$ around the carrions was identified as the most informative predictor variables for estimating PMI with coefficient power of 0.675 while presence of adult clerid beetles $\mathrm{X}_{11}(-$ $0.01366)$ and presence of Dermestes puparium $\mathrm{X}_{15}(0.00449)$ were the variables with the lowest predictive powers. Generally, several reports have documented the importance of fly puparia as entomological evidence in investigations not only to estimate the PMI but also to analyse for presence of drugs or poisonous substances. Greenberg and Kunich (2002) reported that presence of amber coloured puparia of Phaenicia (Lucilia) sericata on a body was used as the critical evidence in determination of PMI of a double murder in Chicago. Campobasso et al. (2004) also reported that accumulation of amitryptilyne in the puparia of Megaselia scalaris was used as important information in determination of cause of death. This implies that since the pupa usually have a longer duration on carrions than the eggs and larval stages combined the presence of empty puparia indicates that the adult calliphorid tlies had visited the body and laid eggs and also shows that the eggs have developed to larvae and hatched to adults.

The presence of clerid and dermestes beetles consistently at all stages of decomposition except 
during the fresh stages show that their degree of contribution to PMI prediction was reduced. This study has shown potentials for the suceess of further estimates of PMI using the model proposed.

\section{ACKNOWLEDGENIENTS}

We thank the Zoology and Environmental Biology Department of Lagos State University and the Animal Science Department of the Faculty of Agriculture, Ahmadu Bello University, Zaria for allowing the study to be conducted in their premises, and the insect museum at the Institute of Agricultural Research, IAR, Samaru, Kaduna State for identification of the insect sanıples.

\section{REFERENCES}

Anderson, G. S. (1995). The use of insects in death investigations: an analysis of cases in British Columbia over a five-year period. Canadian Society of Forensic Science Journal, 28 (4): 277-292.

Anderson, G. S. (2001). Succession on carrion and its relationship in determining time of death. In: Byrd J. H and Castner J. L. (Eds.) Forensic Entomology: the Utility of Arthropods in Legal Investigations. CRC Press, Boca Raton, Florida, 143-175.

Braack, L.E.O. (1981). Visitation pattern of principal species of the insect-complex at carcasses in the Kruger National Park. Kocdoe, 24:33-49.

Brown, K., Thorne, A., and Harvey M. (2015). Calliphora vicina (Diptera: Calliphoridae) pupae: a timeline of external morphological development and a new age and PMI estimation tool. International Journal of Legal Medicine, 129:835-850.

Byrd, J. H. and Castner, J. L. (2010). Insects of Forensic Importance. In: Byrd, J.H.and Castner, J. L. (Eds). Forensic Entomologl: The Etility of Arthropods in Legal Investigations. 2nd Edition. CRC Press Boca Raton. 39-126.

Campobasso, C.P., Disney, R. II. L. and Introna, F. (2004). A case of Megaselia scalaris (Locw) (Dipt., Phoridae) breeding in a human corpse. Agrantraal's internet Jommal of Forensic Medicine and Toxicologr: 5(1):3-5.

Catts, E. P. and Goff, M. L. (1992). Forensic entomology in criminal investigations. Annual Revien of Entomologr:37:253-272.

Catts, E.P. and Haskell, N. H. (1990). Entomology and Death: A Procedural Guide. Joyce's Print Shop, Inc. Clemson, South Carolina. 180pp.

Foran, D. R. (2007). Generating more precise postmortem interval estimated with entomological evidence: Reliable patterns of gene expression throughout Calliphorid larval and pupal development. Submitted to the US Department of Justice. NCJR. 189pp.

Retrieved from: www.ncjr.gov/pdffiles/nij/grants/219503

Goff, M. L. (2010). Early Postmortem Changes and Stages of Decomposition. In: Amendt J., Goff, M. L., Campobasso, C. P., and Grassberger, M.(Eds.), Current concepts in Forensic Entomologi; Springer Science and Business Media. Dordrecht. 1-24.

Goff, M. L., Alvin, I.O. and Gunatilake, K. (1988). Estimation of postmortem interval by arthropod succession. Three case studies from Hawaiian Islands. American Journal of Forensic Medicine and Pathology, 9: 220-225.

Greenberg, B. and Kunich, J. C. (2002). Entomologr: and the Law: Flies as Forensic Indicators. Cambridge University Press, England.306pp.

Kashyap, V. K. and Pillai, V.V.(1989). Efficacy of entomological method in estimation of postmortem interval: a comparative analysis. Forensic Science International, 40: 245-250.

Lord, W.D. and Rodriguez, W. C. (1989). Forensic Entomology: The use of insects in the investigation of homicide and untimely death. The'Prose'cutor, 22 (3): 41-48.

Sharma, R., Garg, R. K. and Gaur, J. R. (2015). Various methods for the estimation of their postmortem interval from Calliphoridae: A revicw: Eglpticun Jounnal of Formencie Seicne's, 5: 1-12.

Smith, K. V. G. (1986). A Mcumual of Forensic Entomology: Trustees of the British Museum (Natural History). London and Cornell University Press, Ithaca, New York. 205pp. 
Tempelman-Kluit, A. (1993). Insects and entomologists become police tools in murder investigations. Conncudian Medical Associution Journal, 148:601-604.

Wells, J. D. and La Notte, L.R. (2010). Estimating the postmortem interval. In: Byrd, J. H. and Castner, J. L. Forensic Entomologl: The Utility of Arthropods in Legal Investigations. CRC Press, Boca Raton, Florida, 367-388.

Wells, J. D. and LaNotte, L. R. (2017). The role of a PMI-prediction model in evaluating forensic entomology experimental design, the importance of covariates, and the utility of response variables for estimating time since death, Insects 8: 47-54.

Wells, J. D., Lecheta, M. C., Moura, N. O., LaNlotte, L. R. (2015). An eraluation of sampling methods used to produce insect growth models for postmortem interval estimation. International Journal of Legal Medicine, 129:405-410.

*Alafia, A.O. , Anikwe', J.C., Denloye", A.A., Ajelara', K.O., Makanjuola', W.A. and Awosanya'. T.

Vigerian Journal of Entomology.

Published by the Entomological Society of Nigeria

WwW.esn.org.ng

ISSN: $0331-(0094$

Volume 3.3. 2017

рр $57-65$

DOI:10.36108/NJE/7102/33(0170) 